\title{
Evidence for thin oceanic crust on the extinct Aegir Ridge, Norwegian Basin, NE Atlantic derived from satellite gravity inversion
}

\author{
E. E. Greenhalgh ${ }^{1}$ and N. J. Kusznir ${ }^{1}$ \\ Received 23 January 2007; revised 17 February 2007; accepted 23 February 2007; published 24 March 2007.
}

[1] Satellite gravity inversion incorporating a lithosphere thermal gravity correction has been used to map crustal thickness and lithosphere thinning factor for the NE Atlantic. Predicted oceanic crustal thicknesses in the Norwegian Basin are between 4 and $7 \mathrm{~km}$ on the extinct Aegir Ridge, increasing to $9-14 \mathrm{~km}$ at the margins, consistent with volcanic margin continental breakup at the end of the Paleocene. The observation (from gravity inversion and seismic refraction studies) of thin oceanic crust produced by the Aegir Ridge in the Oligocene may have implications for the temporal evolution of asthenosphere temperature under the NE Atlantic during the Tertiary. Thin Oligocene oceanic crust may imply cool (normal) asthenosphere temperatures during the Oligocene in contrast to elevated asthenosphere temperatures in the Paleocene and Miocene-Recent as indicated by the formation of volcanic margins and Iceland respectively. Citation: Greenhalgh, E. E., and N. J. Kusznir (2007), Evidence for thin oceanic crust on the extinct Aegir Ridge, Norwegian Basin, NE Atlantic derived from satellite gravity inversion, Geophys. Res. Lett., 34, L06305, doi:10.1029/2007GL029440.

\section{Introduction}

[2] The opening of the NE Atlantic was preceded by intra-continental rifting throughout the Mesozoic, culminating in Early Tertiary continental breakup and the onset of sea-floor spreading at $\sim 55$ Ma between Greenland (including Jan Mayen) and Norway [e.g., Bott, 1985; Mosar et al., 2002]. Continued sea-floor spreading led to the formation of the Reykjanes, Aegir, and Mohns ridges, which were fully developed by $47 \mathrm{Ma}$. A rift developed between Jan Mayen and Greenland and propagated northwards between 40 and $33 \mathrm{Ma}$ [Müller et al., 2001], forming the Kolbeinsey Ridge. Sea-floor spreading along the Aegir Ridge had ceased by $25 \mathrm{Ma}$. Full sea-floor spreading occurred along the Kolbeinsey Ridge by $10 \mathrm{Ma}$, connecting the Mohns Ridge to the Reykjanes Ridge, and separating the Jan Mayen micro-continent from the east coast of Greenland.

[3] The bathymetry of the study area is shown in Figure 1. Elevated bathymetry is observed over the Jan Mayen microcontinent, Iceland, and the Iceland Plateau (the region north of Iceland formed by Kolbeinsey Ridge sea-floor spreading) in comparison to the Norwegian Basin, formed by seafloor spreading along the Aegir Ridge, and the Vøring Plateau. The free-air gravity data [Sandwell and Smith, 1997, Figure 1] shows well-defined maxima over Iceland,

\footnotetext{
${ }^{1}$ Department of Earth and Ocean Sciences, University of Liverpool, Liverpool, UK.

Copyright 2007 by the American Geophysical Union. 0094-8276/07/2007GL029440\$05.00
}

the Jan Mayen micro-continent and the Kolbeinsey Ridge. The Aegir Ridge is defined by a prominent minimum. Recent seismic studies of the area have found oceanic crustal thicknesses vary across the region; the Iceland Plateau exhibits thick oceanic crust [Kodaira et al., 1998] whereas extremely thin crust has been observed in the Norwegian Basin [Breivik et al., 2006]. It has recently been proposed that the Jan Mayen micro-continent may extend into eastern Iceland [Fedorova et al., 2005; Leftwich et al., 2005; Foulger, 2006]. A satellite gravity inversion incorporating a lithosphere thermal gravity anomaly correction has been used to determine the crustal thickness of the NE Atlantic. The results from the inversion have been successfully tested against seismic refraction data.

\section{Crustal Thickness Determination From Gravity Inversion With a Lithosphere Thermal Gravity Anomaly Correction}

[4] Moho topography $\Delta r$ was calculated from the mantle residual gravity anomaly $\Delta g_{m r a}$ using the scheme of Parker [1972].

$$
F\left[\Delta g_{m r a}\right]=2 \pi G \Delta \rho e^{-|k| z_{0}} \sum_{n=1}^{\propto} \frac{(|k|)^{n-1}}{n !} F\left[\Delta r^{n}\right]
$$

Where

$$
\Delta g_{m r a}=\Delta g_{f a g}+\Delta g_{b}+\Delta g_{t}
$$

$\Delta g_{\text {fag }}$ is the observed free air gravity anomaly, $\Delta g_{b}$ is the gravity anomaly from bathymetry and $\Delta g_{t}$ is the lithosphere thermal gravity anomaly; $z_{o}$ is the mean Moho depth, $G=$ $6.67 \times 10^{-11} \mathrm{~m}^{3} \mathrm{~kg}^{-1} \mathrm{~s}^{-2}, \Delta \rho=\rho_{m}-\rho_{c}, F$ denotes a Fourier transform and $k$ is wave number. $\Delta g_{m r a}$ was filtered before the inversion to remove the high frequency components within the data, using a Butterworth low-pass filter with a cutoff wavelength of $100 \mathrm{~km}$. The assumption is made that $\Delta g_{m r a}$ is caused solely by variations in Moho depth. Densities for seawater $\rho_{w}$, crust $\rho_{c}$ and mantle $\rho_{m}$ used in the inversion are $1039 \mathrm{kgm}^{-3}, 2850 \mathrm{kgm}^{-3}$ and $3300 \mathrm{kgm}^{-3}$ respectively.

[5] Crustal thickness $c t$ was calculated from $\Delta r$, where d is Moho depth, $d_{r e f}$ is Moho reference depth and b is bathymetry

$$
\begin{gathered}
d=d_{r e f}+\Delta r \\
c t=d-b
\end{gathered}
$$

$d_{\text {ref }}$ may be determined by calibration using seismic refraction and corresponds to the thickness of crust that has zero bathymetry. A value of $32.5 \mathrm{~km}$ was used in the gravity inversion for the study area. 


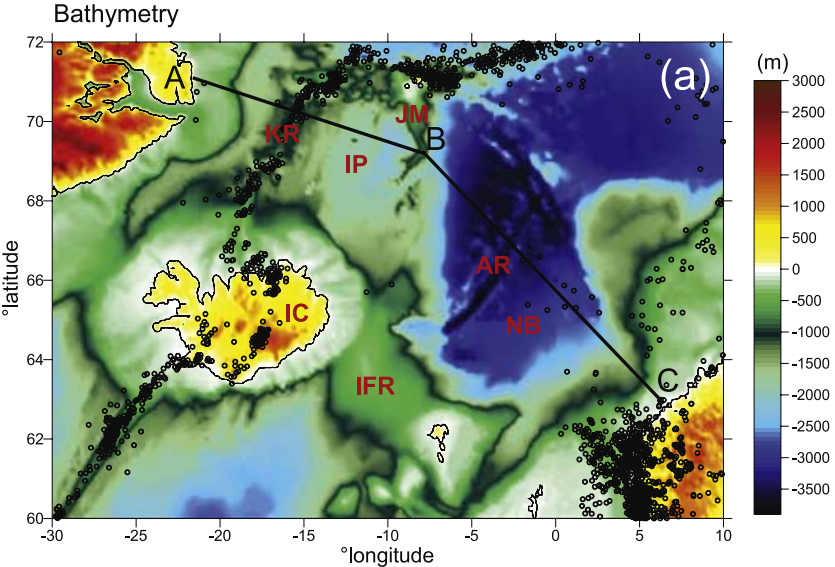

Free-air gravity and isochrons

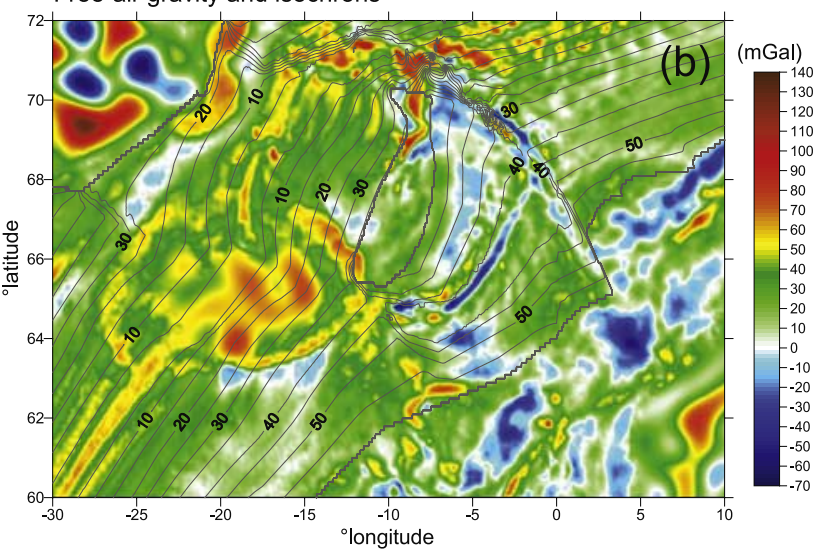

Figure 1. (a) Bathymetry of the NE Atlantic [Intergovernmental Oceanographic Commission et al., 2003], superimposed with USGS earthquake data from 1973 to present. KR, Kolbeinsey Ridge; IP, Iceland Plateau; JM, Jan Mayen micro-continent; IC, Iceland; IFR, Iceland-Faroe Ridge; AR, Aegir Ridge; NB, Norwegian Basin. Line shows location of crustal thickness profile A-B-C in Figure 4. (b) Free-air gravity anomaly [Sandwell and Smith, 1997] and ocean isochrons [Müller et al., 1997] for the NE Atlantic.

[6] Oceanic and rifted continental margin lithosphere have elevated geotherms. The observed thermal gravity anomaly $\Delta g_{t}$ at ocean ridges may be as much as $-380 \mathrm{mGal}$, with lower, but still substantial, values observed away from the ridge and within rifted continental margin lithosphere. The initial perturbation of the geotherm is described by the lithosphere stretching factor $\beta$ [McKenzie, 1978]. $\Delta g_{t}$ is caused by the density contrast $\Delta \rho_{t}$ arising from lateral variations in lithosphere temperature, and has been calculated using $\Delta \rho_{t}=\rho \alpha \Delta T$.

[7] Lithosphere temperature may be calculated using the lithosphere thinning model by McKenzie [1978] and used to predict the lithosphere thermal gravity anomaly correction.

$$
\begin{aligned}
\Delta g_{t}= & \frac{8 G \alpha \rho a T_{m}}{\pi} \\
& \cdot \sum_{m=0}^{\infty} \frac{1}{(2 m+1)^{2}}\left[\frac{\beta}{(2 m+1) \pi} \sin \frac{(2 m+1) \pi}{\beta}\right] \\
& \cdot \exp \left(-\frac{(2 m+1)^{2} t}{\tau}\right)
\end{aligned}
$$

Where: $\mathrm{a}$, the lithosphere thickness $=125 \mathrm{~km} ; \alpha$, the coefficient of thermal expansion $=3.28 \times 10^{-5}{ }^{\circ} \mathrm{C}^{-1} ; \rho$, the lithosphere density $=3300 \mathrm{kgm}^{-3} ; \mathrm{T}_{\mathrm{m}}$, the base lithosphere temperature $=1300^{\circ} \mathrm{C} ; \tau$, the lithosphere cooling thermal decay constant $=65 \mathrm{Ma}$ and $\mathrm{t}$ is the lithosphere thermal equilibration time (Ma). The magnitude of the anomaly is governed by $\beta$ and $t$. For oceanic lithosphere, $\beta=\infty$ and $t$ is the age of the oceanic lithosphere, defined by isochrons. For continental margin lithosphere,

$$
\beta=c t_{0} / c t_{\text {now }}
$$

the ratio of the initial thickness of continental crust $\mathrm{ct}_{0}$ to the present continental crustal thickness $c t_{n o w}$ derived from gravity anomaly inversion; $t$ is the time since continental breakup. Lithosphere thinning is assumed to be equivalent to crustal thinning.

[8] In the absence of oceanic ages from isochrons, or where isochrons are unreliable, an alternative strategy may be used to condition the lithosphere thermal model used to define $\Delta g_{t}$ For this, the whole region is treated as continental lithosphere with values for $\beta$ and $t$ as above. However, this approach fails to predict an increasing thermal anomaly towards the ridge so it over-predicts the crustal thickness in these regions. To overcome this, a combination of the two methods was used, with isochrons defining $t$ in areas of oceanic crust close to the ridge axis and using a uniform breakup age for $t$ nearer the margin. This method gives an independent prediction of the OCT location and marginal crustal thicknesses.

[9] Volcanic addition from the sea-floor spreading process results in the formation of oceanic crust and thickening of the continental crust adjacent to the ocean-continent transition. If $v a$ is the thickness of volcanic addition, then a correction may be made to equation (6):

$$
\beta=c t_{0} /\left(c t_{\text {now }}-v a\right)
$$

$v a$ may be estimated from the lithosphere thinning factor $\gamma$, where $\gamma=1-1 / \beta$, using the adiabatic decompression melt generation model predictions of White and McKenzie [1989] and Bown and White [1994]. For this we must define a critical thinning factor for the initiation of oceanic crust production, and a maximum oceanic crustal thickness; for this study area, values of 0.5 and $10 \mathrm{~km}$ were used respectively, consistent with melt production at volcanic margins. An iterative cycle of gravity inversion to predict crustal thickness, $\beta$ stretching factor, volcanic addition and lithosphere thermal gravity anomaly is used and rapidly converges. In the absence of reliable sediment thickness data, the gravity inversion scheme used in this paper produces an upper bound of crustal thickness and a lower bound of lithosphere thinning factor.

\section{Crustal Thickness and Lithosphere Thinning Factor Distribution Predicted by Gravity Anomaly Inversion}

[10] The crustal thickness from gravity inversion was initially calculated with no thermal gravity correction (Figure 2a). This produced an over-estimate of the crustal 


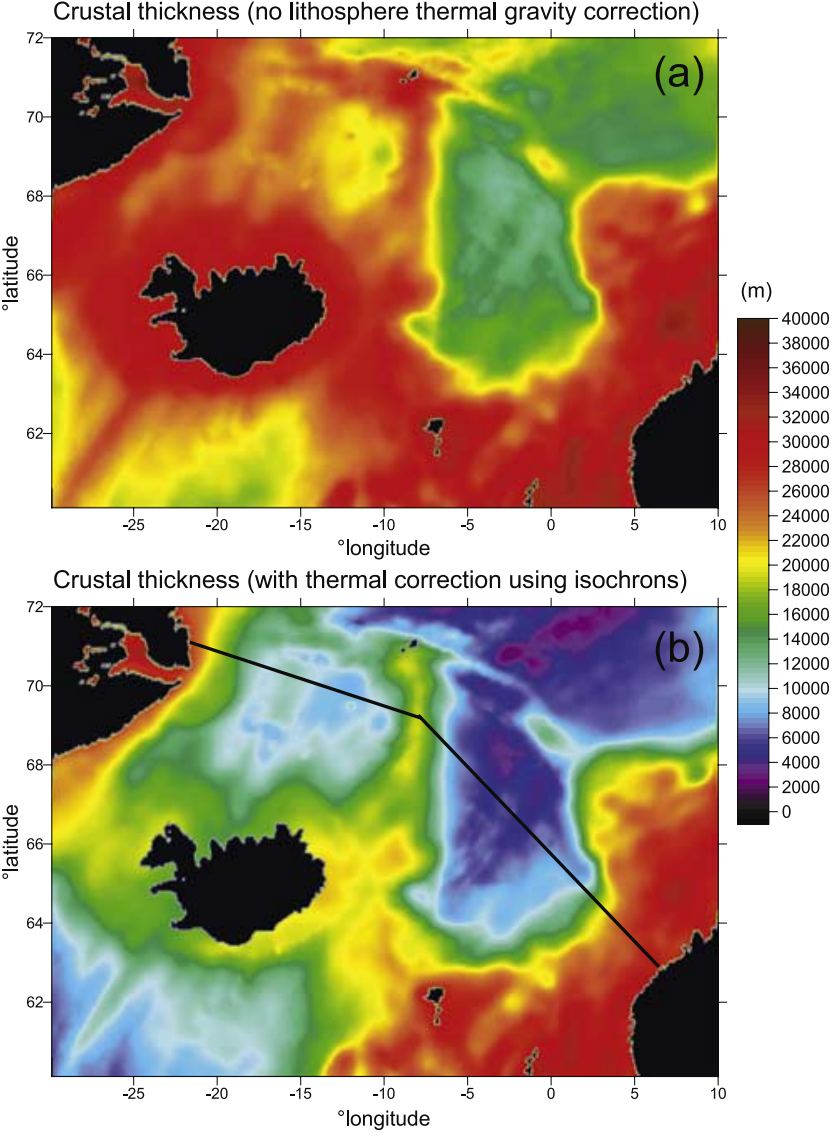

Figure 2. Crustal thickness predicted by the gravity inversion (a) with no lithosphere thermal gravity anomaly correction and (b) with a lithosphere thermal gravity anomaly correction computed using oceanic isochrons from Müller et al. [1997].

thickness, with values for the Norwegian Basin of $\sim 15 \mathrm{~km}$, for the Faroes-Iceland Ridge $\sim 28 \mathrm{~km}$, and $\sim 22 \mathrm{~km}$ for the Iceland Plateau. The predicted oceanic crustal thicknesses with the lithosphere thermal gravity anomaly correction included in the inversion (Figure 2b) are more consistent with seismic observations: $9 \mathrm{~km}$ for the Iceland Plateau [Kodaira et al., 1998] and 4-11 km for the Norwegian Basin [Breivik et al., 2006]. Thicker crust (cf. ocean basins) is predicted for the Jan Mayen micro-continent south of Jan Mayen Island, with crust of the order of $20 \mathrm{~km}$ thickness extending southwards to connect with both the FaroesIceland Ridge and NE Iceland. Predicted crustal thicknesses under the Faroes-Iceland Ridge are approximately $25 \mathrm{~km}$. The thermal correction used to compute Figure $2 b$ uses oceanic isochron data from Müller et al. [1997].

[11] Figure 3a shows the results from the gravity inversion for the Norwegian Basin using ocean isochrons younger than $40 \mathrm{Ma}$ with the remaining area assumed to be continental and having a breakup age of $55 \mathrm{Ma}$. The predicted oceanic crustal thickness of the Aegir Ridge is as low as $4 \mathrm{~km}$, increasing to $14 \mathrm{~km}$ at the Møre margin. Predicted crustal thicknesses for the Faroes-Iceland Ridge and the Jan Mayen micro-continent are $\sim 24 \mathrm{~km}$ and $\sim 19 \mathrm{~km}$ respectively. Very thin oceanic crust $(\sim 2 \mathrm{~km})$ is also predicted for the Vøring Basin. The continental lithosphere thinning predicted from the gravity inversion is shown in Figure $3 \mathrm{~b}$. It shows a thinning factor of 1 in definite oceanic regions, with thinning decreasing towards the continental margins of Norway and Jan Mayen, and over the FaroesIceland Ridge.

[12] The gravity inversion has also been applied to the Iceland Plateau, using ocean isochrons younger than $20 \mathrm{Ma}$ and a breakup age of $30 \mathrm{Ma}$. The predicted crustal thicknesses from this inversion (Figure 3c) show thicker crust extending from the Jan Mayen micro-continent through to Iceland and the Faroes-Iceland Ridge. The map shown in Figure $3 \mathrm{c}$ is only applicable to the west side of Jan Mayen because of the younger rift age used in determining the lithosphere thermal gravity anomaly correction. A maximum crustal thickness of $\sim 18 \mathrm{~km}$ is observed over the Jan Mayen micro-continent, with a value of $\sim 9 \mathrm{~km}$ obtained for much of the ocean basin region north of Iceland. The Faroes-Iceland Ridge has a crustal thickness of $\sim 26 \mathrm{~km}$ at its maximum. Maximum thinning occurs in the area represented by ocean isochrons. There is also a region of more thinned crust immediately west of the ridge above $68^{\circ}$ in the Jan Mayen Basin. Lower thinning factors are seen over areas assumed in the inversion to be continental.

[13] In Figures 2 and 3, a clear continent-ocean boundary exists to the east of the Jan Mayen micro-continent, terminated by the Faroes-Iceland Ridge to the south. There is a rapid transition from the continental crust of the Jan Mayen micro-continent to the oceanic crust of the Norwegian Basin. The different approaches used to determine the lithosphere thermal gravity anomaly correction predict similar ocean-continent transition locations, although crustal thicknesses vary slightly in some areas. To the west of the Jan Mayen micro-continent, the location of the oceancontinent transition is not well defined, particularly in the south towards Iceland.

\section{Discussion and Summary}

[14] The bathymetry and Moho depth calculated from the gravity inversion using the lithosphere thermal gravity anomaly correction are shown for profile A-C in Figure 4. Crustal thickness decreases from Greenland towards the oceanic crust formed by the Kolbeinsey Ridge, where a minimum crustal thickness of $8 \mathrm{~km}$ is observed immediately to the west of the Jan Mayen micro-continent. The crust then thickens under the Jan Mayen micro-continent, reaching $19 \mathrm{~km}$ at its thickest. The crust thins again into the Norwegian Basin, where the minimum crustal thickness observed along this profile is $\sim 4.5 \mathrm{~km}$. The crust then thickens towards the Norwegian margin.

[15] Breivik et al. [2006] derived crustal thickness for the Aegir Ridge using refraction seismology. They determined that the oceanic crust formed along the continental margin during the initial stages of opening was $10-11 \mathrm{~km}$ thick, decreasing to $5.3 \mathrm{~km}$ between 51 and $43 \mathrm{Ma}$. For ages younger than $43 \mathrm{Ma}$, they observed a further decrease in oceanic crustal thickness to $3.9 \mathrm{~km}$, corresponding to a decrease in sea-floor spreading rates. The crustal thickness for the Norwegian Basin predicted by the gravity inversion is consistent with these values.

[16] The observation of thin oceanic crust produced by the Aegir Ridge in the Oligocene is inconsistent with what 

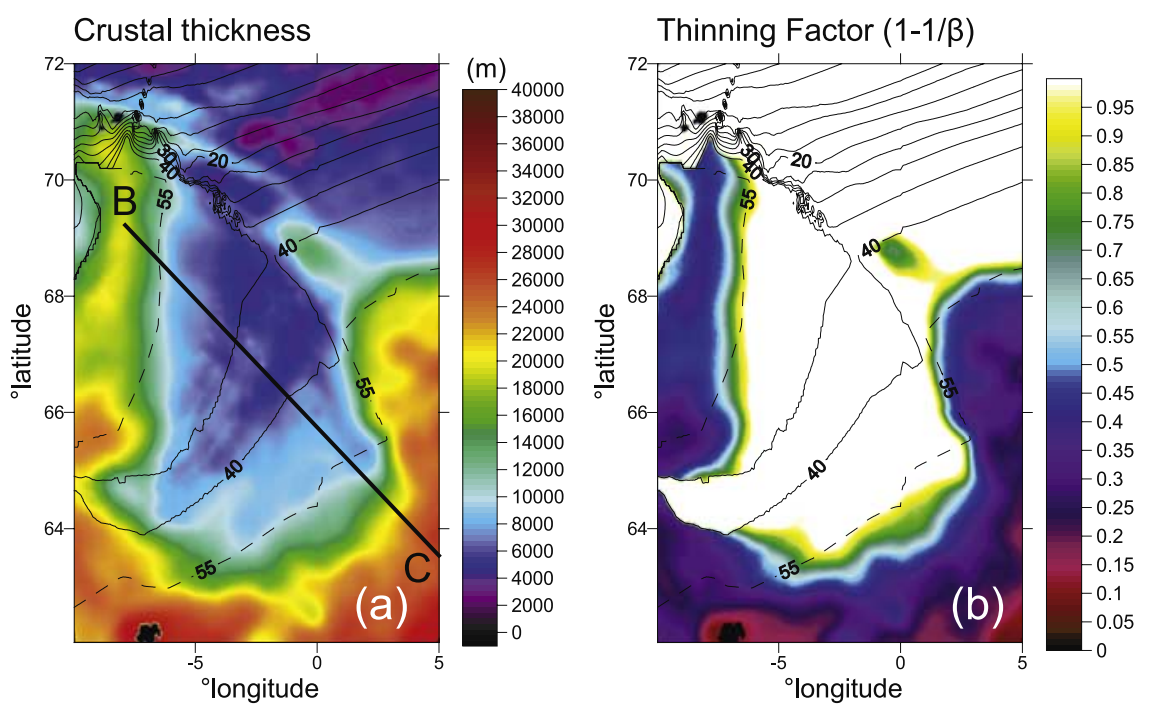

Crustal thickness

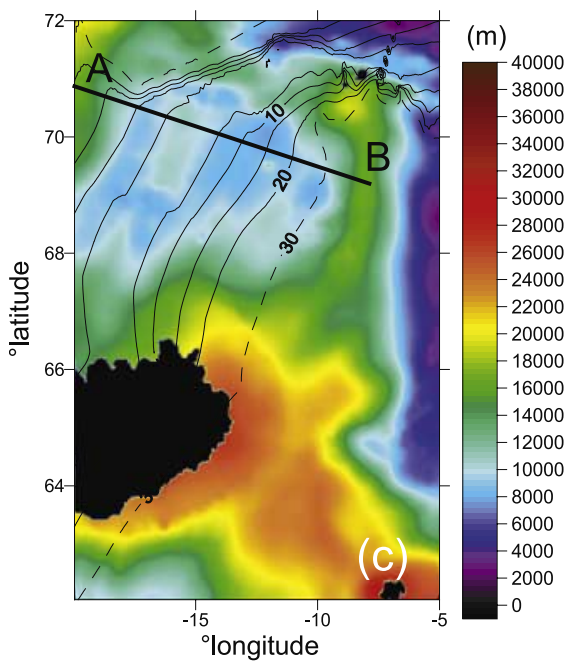

Thinning Factor $(1-1 / \beta)$

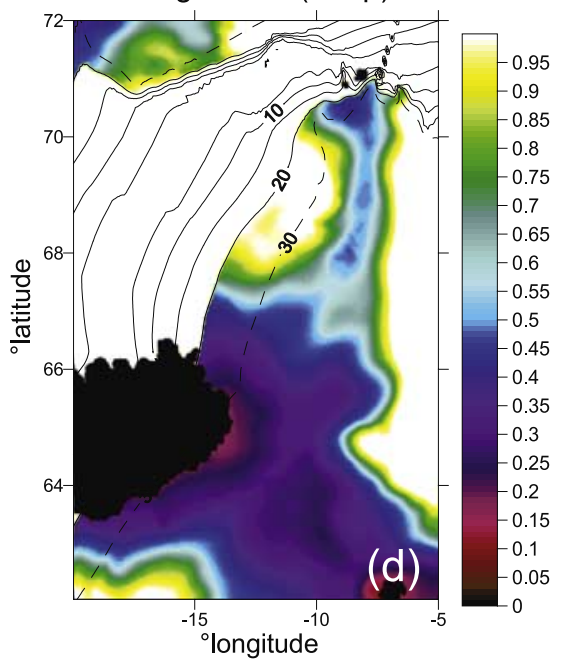

Figure 3. (a) Predicted crustal thickness for the Norwegian Basin, formed by sea-floor spreading on the Aegir Ridge, using oceanic isochrons younger than $40 \mathrm{Ma}$ and breakup age $=55 \mathrm{Ma}$. Location of isochrons are shown. (b) Corresponding predicted lithosphere thinning factor for the Norwegian Basin. (c) Predicted crustal thickness for the region north of Iceland, formed by sea-floor spreading on the Kolbeinsey Ridge, using oceanic isochrons younger than 20 Ma and breakup age $=30$ Ma. Location of isochrons are shown. (d) Corresponding predicted lithosphere thinning factor for the region north of Iceland.

would be expected if there were anomalously hot asthenosphere heated by a mantle plume under the northern North Atlantic at this time [White and McKenzie, 1989]. White [1997] has proposed cool (normal) asthenosphere temperatures during Oligocene sea-floor spreading south of the Faroes-Iceland Ridge on the evidence of oceanic fracture zone morphology and decreased oceanic crustal thickness. Bown and White [1994] and Dick et al. [2003] have proposed that oceanic crustal thickness decreases with sea-floor spreading rate. Breivik et al. [2006] show that Aegir Ridge sea-floor spreading half-rates decreased to $6-8 \mathrm{mmyr}^{-1}$ during the Oligocene, falling within the category of ultraslow sea-floor spreading proposed by Dick et al. [2003]. A combination of cooler (normal) asthenosphere temperature and very slow sea-floor spreading rates may be responsible for the observed thin oceanic crust $(\sim 4 \mathrm{~km})$ produced at the

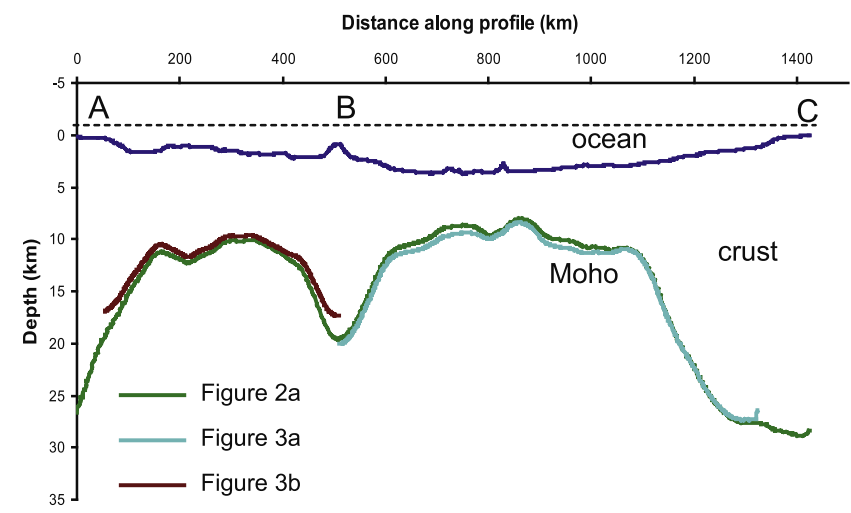

Figure 4. Profile of bathymetry and Moho depth along profile A-B-C (location shown in Figure 1). 
Aegir Ridge in the Oligocene. Thin Oligocene oceanic crust may imply cool (normal) asthenosphere temperatures during the Oligocene in contrast to elevated asthenosphere temperatures in the Paleocene and Miocene-Recent as indicated by volcanic margin formation and the formation of Iceland respectively.

[17] An alternative explanation for thin oceanic crust on the Aegir Ridge has been proposed by Breivik et al. [2006] who suggest that thin oceanic crust may be caused by depletion of the asthenosphere during the construction of the Faroes-Iceland Ridge by the Iceland plume. Mantle compositional heterogeneity, as proposed by Foulger and Anderson [2005], cannot be ruled out as contributing to variations in Aegir Ridge oceanic crustal thickness.

[18] The maximum crustal thickness of Jan Mayen predicted from the seismic data is $15 \mathrm{~km}$ [Kodaira et al., 1998], less than the values obtained from the gravity inversion $(19 \mathrm{~km})$. The presence of sediments on the ridge has not been incorporated into the gravity inversion because of lack of data; including a sediment correction in the calculations would decrease the crustal thickness estimation in areas with thick sediment coverage. Both gravity inversion and seismic methods [Kodaira et al., 1998] predict $\sim 9 \mathrm{~km}$ thickness of oceanic crust produced by Miocene sea-floor spreading on the Kolbeinsey Ridge; this thick oceanic crust may have been generated by sea-floor spreading with elevated asthenosphere temperatures [Kodaira et al., 1998].

[19] A band of thicker crust is predicted by the gravity inversion to extend south from Jan Mayen and connects with Iceland and the Faroes-Iceland Ridge. Both Darbyshire et al. [2000] and Foulger et al. [2003] found thicker crust in eastern Iceland ( $35 \mathrm{~km}$ and $\sim 30 \mathrm{~km}$ respectively) compared to western Iceland $(20 \mathrm{~km})$, where the crust thins away from the centre of the thermal anomaly. This distribution of crustal thickness is not as expected from an eastward migrating plume [Foulger et al., 2003]. Leftwich et al. [2005] found an abrupt change in the Moho depths determined from the seismic and gravity data in eastern Iceland. This may represent a change in crustal composition under eastern Iceland, as their results appear to show a connection between NE Iceland and the Jan Mayen micro-continent, a conclusion also reached by Fedorova et al. [2005]. Foulger [2006] argues the need for older crust to underlie Iceland based on spreading rates and the age of the oldest outcropping rocks in north-west and eastern Iceland and their separation, and suggests that part of this underlying crust may be a thin sliver of the Jan Mayen micro-continent captured beneath Iceland.

[20] Gravity inversion can be used to map 3D crustal thickness where seismic estimates are available for calibration. The method detailed in this paper has also been successfully applied to Atlantic non-volcanic rifted continental margins and the Eurasia and Amerasia basins of the Arctic Ocean [Alvey et al., 2006].
[21] Acknowledgments. We would like to thank members of the iSIMM team and an anonymous reviewer for useful discussions and comments.

\section{References}

Alvey, A. D., C. Gaina, N. J. Kusznir, and T. H. Torsvik (2006), Testing plate reconstructions for the high arctic using crustal thickness mapping from gravity inversion, Eos Trans. AGU, 87(52), Fall Meet. Suppl., Abstract OS53B-1121.

Bott, M. H. P. (1985), Plate tectonic evolution of the Icelandic transverse ridge and adjacent regions, J. Geophys. Res., 90, 9953-9960.

Bown, J. W., and R. S. White (1994), Variation with spreading rate of oceanic crustal thickness and geochemistry, Earth Planet. Sci. Lett., 121(3-4), 435-449.

Breivik, A. J., R. Mjelde, J. I. Faleide, and Y. Murai (2006), Rates of continental breakup magmatism and seafloor spreading in the Norway Basin-Iceland plume interaction, J. Geophys. Res., 111, B07102, doi:10.1029/2005JB004004.

Darbyshire, F. A., R. S. White, and K. F. Priestley (2000), Structure of the crust and uppermost mantle of Iceland from a combined seismic and gravity study, Earth Planet. Sci. Lett., 181, 409-428.

Dick, H. J. B., J. Lin, and H. Schouten (2003), An ultraslow-spreading class of ocean ridge, Nature, 426, 405-412.

Fedorova, T., W. R. Jacoby, and H. Wallner (2005), Crust-mantle transition and Moho model for Iceland and surroundings from seismic, topography, and gravity data, Tectonophysics, 396, 119-140, doi:10.1016/j.tecto. 2004.11.004.

Foulger, G. R. (2006), Older crust underlies Iceland, Geophys. J. Int., $165(2), 672-676$

Foulger, G. R., and D. L. Anderson (2005), A cool model for the Iceland hotspot, J. Volcanol. Geotherm. Res., 141, 1-22, doi:10.1016/j.jvolgeores. 2004.10.007

Foulger, G. R., Z. Du, and B. R. Julian (2003), Icelandic-type crust, Geophys. J. Int., 155, 567-590.

Intergovernmental Oceanographic Commission, International Hydrographic Organization, and British Oceanographic Data Centre (2003), Centenary Edition of the GEBCO Digital Atlas [CD-ROM], Br. Oceanogr. Data Cent., Liverpool, U. K.

Kodaira, S., R. Mjelde, K. Gunnarsson, H. Shiobara, and H. Shimamura (1998), Structure of the Jan Mayen microcontinent and implications for its evolution, Geophys. J. Int., 132, 383-400.

Leftwich, T. E., R. R. B. von Frese, L. V. Potts, H. R. Rae Kim, D. R. Roman, P. T. Taylor, and M. Barton (2005), Crustal modeling of the North Atlantic from spectrally correlated free-air and terrain gravity, J. Geodyn., 40, 23-50, doi:10.1016/j.jog.2005.05.001.

McKenzie, D. (1978), Some Remarks on the development of sedimentary basins, Earth Planet. Sci. Lett., 40, 25-32.

Mosar, J., G. Lewis, and T. H. Torsvik (2002), North Atlantic sea-floor spreading rates: Implications for the Tertiary development of inversion structures of the Norwegian-Greenland Sea, J. Geol. Soc. London, 159, $503-515$.

Müller, R., W. R. Roest, J.-Y. Royer, L. M. Gahagan, and J. G. Sclater (1997), Digital isochrons of the world's ocean floor, J. Geophys. Res., $102,3211-3214$.

Müller, R. D., C. Gaina, W. R. Roest, and D. L. Hansen (2001), A recipe for microcontinent formation, Geology, 29(3), 203-206.

Parker, R. L. (1972), The rapid calculation of potential anomalies, Geophys. J.R. Astron. Soc., 31, 447-455.

Sandwell, D. T., and W. H. F. Smith (1997), Marine gravity anomaly from Geosat and ERS-1 satellite altimetry, J. Geophys. Res., 102, 10,03910,054 .

White, R. S. (1997), Rift-plume interaction in the North Atlantic, Philos. Trans. R. Soc. London, Ser. A, 355, 319-339.

White, R., and D. McKenzie (1989), Magmatism at rift zones: The generation of volcanic continental margins and flood basalts, J. Geophys. Res., $94,7685-7729$.

E. E. Greenhalgh and N. J. Kusznir, Department of Earth and Ocean Sciences, University of Liverpool, Liverpool L69 3BX, UK. (erica.greenhalgh@liverpool.ac.uk) 